\title{
Availability as an Operational Efficiency Indicator of Medical Equipment
}

\author{
Gleb Donin*, Peter Kneppo \\ Department of Biomedical Technology, Faculty of Biomedical Engineering, Czech Technical University in Prague, Nám. Sítná 3105, 27201 \\ Kladno, Czech Republic
}

\section{BIOGRAPHICAL NOTES}

Gleb Donin, Ing. graduated from Bauman Moscow State Technical University, with a specialty in Biomedical Devices and Systems (MSc in 2008). He worked for the Russian Scientific, Research and Testing Institute of Medical Equipment as head of information and technical support services in the Department of Monitoring of Medical Devices. He has been involved in the development of the informational system for monitoring medical devices in the Russian Federation. He is currently studying at the Faculty of Biomedical Engineering, Czech Technical University in Prague, in a Biomedical and Clinical Technology doctoral program. His main areas of interest are medical device regulation, methods of monitoring medical devices, and using obtained information in HTA.

Peter Kneppo, prof. Ing., DrSc. completed his education at the Technical University of Power Engineering in Moscow (MSc in 1964), followed by a PhD in Measurement Instrumentation at the Institute for Measurement Theory, Bratislava (1972); he then earned his DSc in Measurement Science at Slovak Academy of Sciences (1983). He worked for the Metra Blansko Company in the Czech Republic (1964-1965), then at the Institute of Measurement Science, Slovak Academy of Sciences, as a senior research scientist, where he was promoted to scientific director (1977-1990). As a technical director at the Chirana Prema Company (1992-1994), he took a leading role in the development and implementation of new medical devices, and served as the general director of the Slovak Institute of Metrology, Bratislava, Slovakia, in the global metrological system. He has published five books and more than 300 other publications dealing with measurements and modeling in medicine and metrology, thus continuing with his research on biomedical measurement and medical instrumentation, especially measurement and modeling of the cardiac electric and magnetic fields, medical metrology, and quality management.

\section{KEYWORDS}

Medical equipment; operation efficiency; availability; efficiency indicator.

\begin{abstract}
The problem of operational efficiency assessment of purchased medical equipment is becoming critical, due to increasing public spending on medical devices. It has been shown that a significant amount of medical equipment is not in an operable state, for many different reasons. Commonly used complex operational efficiency indicators take the standby and down states of medical equipment into account together, as they do not have the potential to provide separate analyses of the efficiency of medical device management at healthcare facilities. Thus, the goal of this study was to identify and describe indicators for a more detailed assessment of operational ef-
\end{abstract}


ficiency of medical equipment in terms of different causes of the standby state. Systematization of causes of the standby state was implemented based on the performance data of different types of medical equipment. Managerial availability was developed as a measure of the operational efficiency of medical equipment, based on separating the standby state from the down state. Additional operational efficiency indicators found on components of standby time of medical equipment were suggested. The proposed indicators were calculated for some types of medical equipment as examples of its application. Proposed managerial availability levels and corresponding thresholds were suggested.

\section{Introduction}

Post-market surveillance is an important element of public policy to ensure the quality and safety of health care [1]. Control of the operational efficiency of medical equipment as a component of post-market surveillance is significant for regional health authorities and healthcare facilities themselves [2].

Given the current growth in spending on medical devices, it is very important to provide the highest levels of operational efficiency [2], [3]. However, a large quantity of medical equipment is not in an operable state, due to different reasons, such as a lack of staff, lack of technical services, and lack of finances to provide the maintenance [2].

The Supreme Audit Office of the Czech Republic has pointed out that public procurement of medical equipment for university hospitals during 2006-2011 was carried out without previous allocations of state analyses of already used devices, which increases the risk of inefficient spending of financial resources. In addition, the purchased medical equipment remains without proper control by the authorities [4]

Therefore, it is necessary to develop new operational efficiency indicators for medical equipment in order to carry out multi-criteria monitoring during the lifecycle of medical devices and to make reasonable decisions regarding their management.

This paper is devoted to the analysis of operating efficiency indicators for medical equipment, excluding clinical efficiency. The aim of this study was to design additional indicators of operational efficiency based on the term of availability of medi- cal equipment, as availability characterizes the efficiency of the organization of operation processes of medical equipment from a practical point of view.

\section{Operational Efficiency of Medical Equipment}

In general, the operational efficiency of technical equipment is comprised of several components that characterize different aspects of the operating process, and it is defined by a set of corresponding indicators. It is common practice to point out the following components of operational efficiency: reliability, productivity, and availability [5]. The reliability of medical equipment is mainly specified at the manufacturing/production phase of the lifecycle and supported by maintenance processes [6]. Due to the specificity of the healthcare process, productivity cannot be objectively determined for all types of medical equipment. Availability is an important evaluating criterion for repairable systems, as it takes into account both reliability and maintainability properties of the system [7].

Availability is defined as "a percentage measure of the degree to which machinery or equipment is in an operable and committable state at the point in time when it is needed" [7]. By taking different definitions for this state, following types of availability are practically used: inherent, achieved, and operational availability. Operational availability is the most widely used for the complex assessment of the operational efficiency of equipment.

Operational availability is mean availability for a specific period, which takes into account planned and unplanned maintenance, administrative, and logistic delays and other causes of equipment downtime [7]. Operational availability is the result of events that occur during the lifecycle of the equipment. Operational availability is commonly defined as [7], [8], [9]:

$$
A_{o}=\frac{U T}{O C}=\frac{U T}{U T+D T}
$$

where UT = uptime, the time during which equipment is operable and is able to perform its function; DT = downtime, the time during which equipment does not perform its function; and $\mathrm{OC}=$ operating cycle, the total duration of the considered time interval.

Operational availability is commonly used to assess the efficiency of medical equipment mainte- 
nance processes [10], [11], [12]. This indicator is also used to assess the operational efficiency of medical equipment, both as a part of overall equipment efficiency [13] and separately as a standalone indicator [14].

In terms of operational efficiency analysis, the following components of uptime can be defined [7], [15], [16], [17], [18]:

-Operating time (OT) - the time during which the equipment is in an operable state and performs its function,

- Idle time (IT) - the time during which the equipment is in an operable state and does not perform its function, in accordance with the schedule,

-Standby time (ST) - the time during which the equipment is in an operable state and does not perform its function, not in accordance with the schedule.

In this case, the time during which the equipment is not in an operable state (corrective maintenance time (CMT) and preventive maintenance time (PMT)) is referred to as downtime (Figure 1). Based on the definition above, operational availability can be defined as:

$$
A_{o}=\frac{O T+I T}{O C}=1-\frac{D T+S T}{O C}
$$

The numerator of the second term in Equation (2) combines the downtime, caused by technical reasons, and the standby time, caused by organizational reasons, such as administrative and logistic delays. Therefore, the evaluation of the complex indicator, operational availability, is not enough to make informed management decisions, and it is necessary to define certain types of causes of the standby state of the medical equipment [19].

\section{Causes of Standby State of Medical Equipment}

Four recently purchased equipment groups were selected to carry out the classification of possible causes of their standby state. The state of the selected medical equipment was observed, and every standby time interval was recorded, along with the associated reason. The observed causes of the standby state were classified into six basic groups for further analysis: no demand, administrative delays, lack of facilities, lack of staff, lack of consumables, and lack of components (Figure 1).

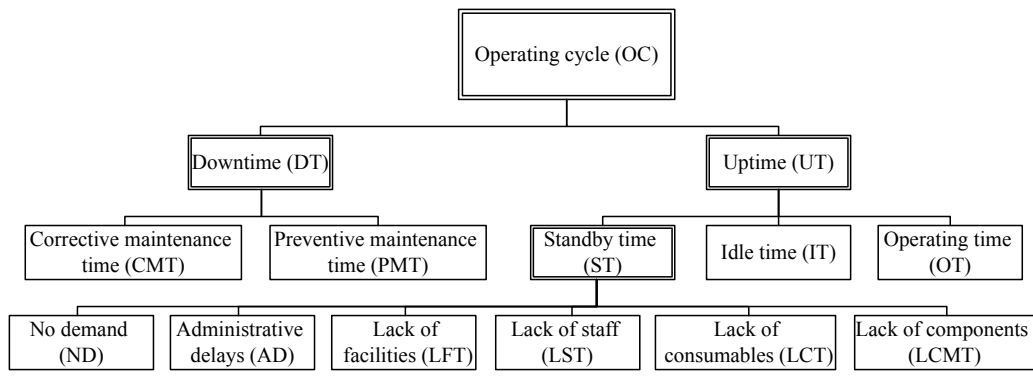

Fig. 1: Summarized groups of time in the operating cycle of medical equipment.

The standby state may be caused by lack of staff, when the operable equipment is not functioning due to an unscheduled lack of personnel or a vacant medical device operator position in the hospital. Lack of consumables time is related to problems with the supply of consumables necessary to operate the medical equipment, and lack of components time is caused by unavailability of the components (options) required for proper equipment operation. The condition of the facility and its preparedness for use of the devices (lack of facilities) is a frequent cause of standby state of medical equipment, when the rooms or units at the hospital are not prepared for operating medical equipment or there is a lack of required utilities.
It is necessary to highlight the periods of administrative delays, related to obtaining the appropriate permissions for using the medical equipment. We should also highlight the no demand period, during which there are no indications that a certain piece of medical equipment is needed. The causes of the standby state and the related periods of operational cycle listed above are often found in studies concerned with evaluating the operational efficiency and maintenance of medical equipment [2], [13], [20], [21].

\section{Managerial Availability and Additional Opera- tional Efficiency Indicators for Medical Equipment}


Taking into account that issues of preventive and corrective maintenance of medical equipment in developed countries are solved at a high performance level, the problem of efficient management of medical equipment in healthcare facilities should be considered separately. Based on the standby period of uptime in the medical equipment operating cycle, a new subtype of availability can be distinguished-managerial availability.

Managerial availability is defined as the proportion of uptime during which the equipment is in an operable state and able to perform its function at the point in time when it is needed, or it is in a scheduled idle state, without taking into account scheduled maintenance. Managerial availability provides the possibility of measuring the efficiency of the medical equipment management processes. Based on the definition stated above, managerial availability can be defined as:

$$
A_{m}=\frac{O T+I T+N D}{U T}
$$

The numerator in Equation (3) represents the time interval during which the equipment is in an operable state, performs its function, or is not used as planned. The no demand time intervals are counted in, as for most medical devices, this state does not characterized the efficiency of medical equipment management in the healthcare facility.

Based on practical performance data obtained from the computerized maintenance management system (CMMS) and other information systems in hospitals [22], managerial availability can be redefined as:

$$
\begin{aligned}
& A_{m}=\frac{U T-S T+N D}{U T}=1-\frac{S T-N D}{U T}= \\
& =1-\frac{S T-N D}{O C-D T}
\end{aligned}
$$

The same approach based on separation of causes of inefficiency can be applied to the indicator suggested above. By using the components of standby time, it is possible to propose additional operational efficiency indicators (Table 1), which characterize certain factors of medical equipment operation. Consumables support index can be defined as an example:

$$
I_{C}=1-\frac{L C T}{O T+S T}
$$

The second term in Equation (5) corresponds to a fraction of the lack of consumables time interval in the scheduled operating period of the medical equipment. For practical applications, Equation (5) can be redefined as:

$$
I_{C}=1-\frac{L C T}{U T-I T}=1-\frac{L C T}{O C-D T-I T}
$$

For the other observed causes of the standby state of medical equipment and the corresponding time intervals, we suggest the corresponding additional operational efficiency indicators shown in Table 1.

Table 1: Additional operational efficiency indicators for medical equipment.

\begin{tabular}{|l|c|}
\hline Indicator & Expression for item \\
\hline $\begin{array}{l}\text { Consumables support } \\
\text { index }\end{array}$ & $I_{C}=1-\frac{L C T}{O C-D T-I T}$ \\
\hline $\begin{array}{l}\text { Components support } \\
\text { index }\end{array}$ & $I_{C M}=1-\frac{L C M T}{O C-D T-I T}$ \\
\hline Facility support index & $I_{F}=1-\frac{L F T}{O C-D T-I T}$ \\
\hline Staff support index & $I_{S}=1-\frac{L S T}{O C-D T-I T}$ \\
\hline $\begin{array}{l}\text { Index of administrative } \\
\text { delays }\end{array}$ & $I_{A D}=1-\frac{A D}{O C-D T-I T}$ \\
\hline
\end{tabular}

Application of the managerial availability and additional operational efficiency indicators allow a more comprehensive evaluation of the operational efficiency of medical equipment and improved decision making in the medical equipment management area.

\section{Application of Developed Indicators}

The medical equipment performance data from 21 medium-sized general hospitals was analyzed to determine the main causes of standby time for different groups of medical devices. The information regarding standby and downtime periods during the first 12 months after equipment installation was collected from computerized maintenance management systems for 122 units of laboratory equipment, 22 units of $X$-ray imaging equipment, 48 units of endoscopic devices, and 53 units of ultrasound imaging equipment. The equipment was purchased within one year with public funds. Calculation data for both operational availability and managerial availability are shown in Table 2. 
Table 2: Operational availability and managerial availability calculation of medical equipment during first 12 months following installation.

\begin{tabular}{|l|l|l|l|l|l|l|l|}
\hline Equipment group & $\begin{array}{l}\text { Equipment } \\
\text { quantity }\end{array}$ & $\begin{array}{l}\text { Operating } \\
\text { cycle, } \\
\text { [days] }\end{array}$ & $\begin{array}{l}\text { Down } \\
\text { time, } \\
\text { [days] }\end{array}$ & $\begin{array}{l}\text { Standby } \\
\text { time, } \\
\text { [days] }\end{array}$ & $\begin{array}{l}\text { No demand } \\
\text { time, } \\
\text { [days] }\end{array}$ & $\begin{array}{l}\text { Operational } \\
\text { availability }\end{array}$ & $\begin{array}{l}\text { Managerial } \\
\text { availability }\end{array}$ \\
\hline Laboratory equipment & 122 & 31842 & 461 & 4170 & 671 & $\mathbf{8 5 . 5 \%}$ & $\mathbf{8 9 \%}$ \\
\hline $\begin{array}{l}\text { Ultrasound imaging } \\
\text { equipment }\end{array}$ & 53 & 13833 & 34 & 1037 & 714 & $\mathbf{9 2 . 3} \%$ & $\mathbf{9 8 \%}$ \\
\hline X-ray imaging equipment & 22 & 5742 & 40 & 174 & 9 & $\mathbf{9 6 . 3} \%$ & $\mathbf{9 7 \%}$ \\
\hline Endoscopic devices & 48 & 12528 & 329 & 1873 & 1738 & $\mathbf{8 2 . 4 \%}$ & $\mathbf{9 9} \%$ \\
\hline
\end{tabular}

The managerial availability indicator, which takes into account only organizational causes of the standby state, allows a more accurate assessment of the management and operational efficiency of the medical equipment, compared to operational availability. The differences between these two indicators can be seen in Table 2.

Analysis of the additional operational efficiency indices, including their time trends, makes it possible to operatively take management decisions and evaluate their results [23]. The obtained values of the additional indicators identify the overriding reason for the decline in managerial availability (Figure 2).

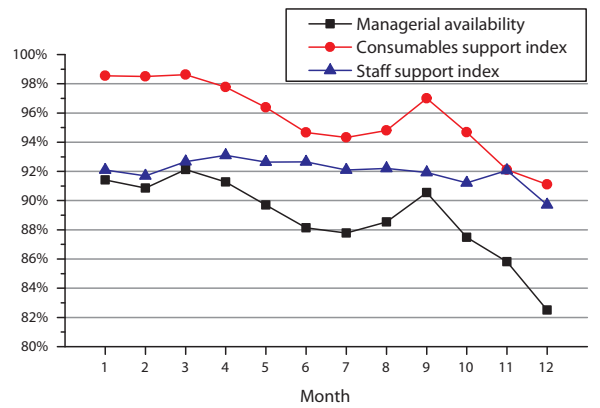

Fig. 2: Managerial availability, consumables support index, and staff support index for 122 units of laboratory equipment during first 12 months following installation.

Analysis of the proposed indicators for medical devices in use is important to clinical engineering departments, as it reveals the inefficient points in the medical equipment operational process. Based on mean values of the proposed indicators, regional health authorities can pinpoint the global problems in the operational efficiency of the medical equipment.

Interpretation of the obtained indicator values is highly dependent on the type of the specific medi- cal equipment, its age, size and type of hospital. For the initial period of medical equipment operation in a medium-sized general hospital in a developing country, we propose the managerial availability levels and corresponding thresholds shown in Table 3. Suggested thresholds can be adjusted to suit the application conditions.

Table 3: Proposed levels and thresholds of managerial availability

\begin{tabular}{|l|l|}
\hline Managerial availability level & $\begin{array}{l}\text { Managerial availability } \\
\text { value threshold }\end{array}$ \\
\hline Very high & $98 \% \leq \mathrm{Am}<100 \%$ \\
\hline High & $95 \% \leq \mathrm{Am}<98 \%$ \\
\hline Medium & $90 \% \leq \mathrm{Am}<95 \%$ \\
\hline Low & $80 \% \leq \mathrm{Am}<90 \%$ \\
\hline Very low & $\mathrm{Am}<80 \%$ \\
\hline
\end{tabular}

The second evaluation indicator was approximate inaccuracy coordinates of contour points. On Fig. 2 are shown the courses of mean value of these inaccuracies.

Similarly, as with number of steps is interval deviation form narrowed, decrease also courses of estimated inaccuracies of coordinates. Approximately, from tenth calibration step is already decline of values less marked.

\section{Conclusion}

The main goal of operational efficiency indicators for medical equipment is to measure how well medical devices are used in hospitals in terms of the main aspects of the operating cycle structure. The different types of operational efficiency indicators, advantages, and limitations of each type have been discussed. Based on the performance data, the causes of standby were analyzed, and new operational efficiency indicators for medical equipment 
were suggested. By taking into account standby time separately from downtime, we proposed a new operational efficiency indicator-managerial availability. Additional operational efficiency indicators were also developed, based on different causes of the standby state of medical equipment.

We have illustrated the application of a proposed indicator and additional criteria to assess the operational efficiency of X-ray and ultrasound imaging equipment, endoscopic devices, and laboratory equipment in medium-sized general hospitals during the 12 months following installation of the equipment.

In contrast to raw indicators, the operational efficiency indicators described herein can provide a more detailed view of the efficiency of medical equipment management in healthcare facilities. The indicators can be used by healthcare providers in identifying weaknesses in the equipment management system and in finding ways to increase operational efficiency. By analyzing values and trends of the indicators, regional healthcare authorities can make informed decisions when assessing the efficiency of medical equipment management in the hospitals, planning new medical equipment procurement, and allocating public funds.

\section{Acknowledge}

This study was funded by grants from The Ministry of Health of the Czech Republic IGA number NT14473 and number NT11532, and SGS13/228/ OHK5/3T/17 by Czech Technical University in Prague.

\section{References}

[1] Cheng, M. (2003). Medical device regulations: global overview and guiding principles. World Health Organization, Geneva.

[2] World Health Organization (2010). Medical devices: managing the mismatch: an outcome of the priority medical devices project. World Health Organization, Geneva.

[3] Skinner, B. (2013). Medical devices and healthcare costs in Canada and 65 other countries, 2006 to 2011. Canadian Health Policy, pp. 1-15.

[4] Nejvyšší kontrolní úřad (2013). Peněžní prostředky určené na rozvoj a obnovu materiálně-technické základny fakultních nemocnic. Věstník Nejvyššího kontrolního úřadu, vol. 2, pp. 163-172.

[5] Godfrey, P. (2002). Overall equipment effectiveness. Manufacturing Engineer, vol. 81, no. 3, pp. 109-112.
[6] World Health Organization (2011). Medical equipment maintenance programme overview. World Health Organization, Geneva.

[7] Katukoori, V. K. (2007). Standardizing Availability Definition. University of New Orleans. New Orleans.

[8] Szawłowski, S., Borgoń, J., Gładyś, S. (2007). Operational Availability Of The Technical Object. Journal of Polish ClMAC, vol. 2, no. 1.

[9] Pryor, G. A. (2008). Methodology for estimation of operational availability as applied to military systems. ITEA Journal, vol. 29, no. 4, pp. 420-428.

[10] Wahed, M. A., Sharawi, A. A., Badawi, H. A. (2010). Modeling of medical equipment maintenance in health care facilities to support decision making. 2010 5th Cairo International Biomedical Engineering Conference, pp. 202-205.

[11] Lo, M. (2004). Benchmarking biomedical equipment maintenance in Hospital Authority (HA). 3rd IEE Seminar on Appropriate Medical Technology for Developing Countries. pp. 13/1-13/5.

[12] Van Horenbeek, A., Pintelon, L. (2014). Development of a maintenance performance measurement framework-using the analytic network process (ANP) for maintenance performance indicator selection. Omega, vol. 42, no. 1, pp. 33-46.

[13] Medhat, N., Samy, S. A., Wahed, M. A., Mohamed, A. S. A. (2008). Medical Equipment Quality Assurance by Making Continuous Improvement to the System. 2008 Cairo International Biomedical Engineering Conference. pp. 1-4.

[14] Dharmaratne, G. S. K., Jayawardana, A. K. L., Gunatunga, M. W. (2010). Integrated Logistic Support and Equipment Availability in Government Hospitals of a Developing Country. Sri Lankan journal of Management, vol. 15, no. 2, 3 \& 4, pp. 79-102.

[15] De Ron, A. J., Rooda, J. E. (2005). Equipment Effectiveness: OEE Revisited. IEEE Transactions on Semiconductor Manufacturing, vol. 18, no. 1, pp. 190-196.

[16] ČSN EN 13306 (2011). Údržba - Terminologie údržby. Český normalizační institut. Praha.

[17] Naeem, H. Bin (2012). Fusion of Operations, Event-log and Maintenance Data. A Case Study for Optimizing Availability of Mining. Luleå University of Technology. Luleå.

[18] Oechsner, R., Pfeffer, M., Pfitzner, L. (2002). From overall equipment efficiency (OEE) to overall Fab effectiveness (OFE). Materials Science in Semiconductor Processing, vol. 5, no. 4-5, pp. 333-339.

[19] Cook, D. (1997). A protocol for the measurement of downtime of medical equipment. British journal of radiology, vol. 70, pp. 279-290.

[20] Somanathan, A., Hanson, K., Dorabawila, T., Perera, B. (2000). Operating Efficiency in Public Sector Health Facilities in 
Sri Lanka: Measurement and Institutional Determinants of Performance. Partnership for Healthcare Reform Project. Bethesda.

[21] Rewar, S. (2012). Research paper:-hospital information system in clinical engineering department. International Journal of Scientific and Engineering Research, vol. 3, no. 8, pp. 797-802.

[22] Xia, L., Zhao, M., Rong, L., Pang, R. (2009). Research on equipment maintenance decision system based on health management. 2009 8th International Conference on Reliability, Maintainability and Safety, pp. 653-657.

[23] Cruz, A. M. (2013). Evaluating record history of medical devices using association discovery and clustering techniques. Expert Systems with Applications, vol. 40, no. 13, pp. 5292-5305. 